\title{
ПОДБОР ТЕХНОЛОГИЧЕСКИХ ПАРАМЕТРОВ ПРОИЗВОДСТВА ОВОЩНЫХ КОНСЕРВОВ
}

\author{
E. V. Shanina
}

\section{THE SELECTION OF TECHNOLOGICAL PARAMETERS OF VEGETABLE CANNED FOOD}

Шанина Екатерина Владимировна - канд. техн. наук, доц. каф. товароведения и управления качеством продукции АПК Красноярского государственного аграрного университета, г. Красноярск. E-mail: kras.olimp@mail.ru

Цель исследования - изучение влияния измельчения (нарезки) овощей и способа их термической обработки на органолептические свойства получаемых овощных консервов (борщевых заправок) и их сохранность. Рассмотрены следующие способы нарезки овощей при производстве обеденных овощных консервов: кубики, соломка, измельчение на крупной терке. Установлено, что наиболее оптимальным способом измельчения является нарезка соломкой - в виде брусочков толщиной 1-2 мм, длиной - 2,5 см. В процессе отработок технологических параметров проведен ряд предварительных исследований получения борщевой заправки методом пассерования и бланширования овощей. Овощные консервы, полученные методом пассерования, характеризуются более насыщенным, выраженным иветом и вкусом. Одной из задач, решаемых в рамках данного исследования, являлось изучение возможности продления сроков хранения овощных консервов (борщевой заправки) без потери их качества. После нарушения герметичности упаковки наиболее длительные сроки хранения (при температуpe + $4{ }^{\circ} \mathrm{C}$ - do 20 cym, при mемпературе $+25^{\circ} \mathrm{C}$ - до 8 сут) были отмечены у борщевой заправки, полученной из пассерованных овощей, нарезанных соломкой. Приведены результаты дегустационной оценки борщевой заправки, которые показали наивысшую оценку (10 баллов) при нарезке овощей соломкой и использовании метода пассерования. Полученные овощные консервы по органолептическим показателям соответствуют требова-
Shanina Ekaterina Vladimirovna - Cand. Techn. Sci., Assoc. Prof., Chair of Merchandizing and Product Quality Control of Agrarian and Industrial Complex, Krasnoyarsk State Agrarian University, Krasnoyarsk. E-mail: kras.olimp@mail.ru

ниям ГОСТ 18316-2013 и могут быть рекомендованы для внедрения в производство.

Ключевые слова: овощные консервы, борщевая заправка, пассерование, бланширование, органолептические показатели, дегустационная оценка, способы нарезки овощей.

The research objective was studying the influence of crushing (cutting) of vegetables and the way of their heat treatment on organoleptic properties of received vegetable canned food (borshch filling) and their safety. The following ways of cutting vegetables were considered while the production of vegetable canned food for dinner: cubes, straws, crushing on a large grater. It was established that the most optimum way of crushing had been cutting by straws in the form of bars with the thickness 1-2 $\mathrm{mm}$, with the length $-2.5 \mathrm{~cm}$. In the course of working out technological parameters a lot of preliminary researches of receiving the borshch filling by the method of browning and scalding of vegetables were carried out. Vegetable canned food received by browning method was characterized by more saturated, expressed color and taste. One of the tasks solved during the research was studying the possibility of the extension of storage periods of vegetable canned food (borshch filling) without the loss of their quality. After the violation of the tightness of packing the longest periods of storage (at the temperature $+4{ }^{\circ} \mathrm{C}$ - to 20 days, at the temperature $+25^{\circ} \mathrm{C}$ to 8 days) were noted for the borshch filling received from browned vegetables cut by straws. The results of tasting assessment of the borshch filling having the highest assessment (10 points) when cutting vegetables straws and using the method of browning 
were given. Received vegetable canned food in organoleptic indicators conforms to the requirements of State Standard 18316-2013 and can be recommended for future production.

Keywords: vegetable canned food, borsch filling, sautéing, blanching, organoleptic indicators, tasting assessment, ways of cutting of vegetables.

Введение. Производство овощных обеденных консервов, в том числе овощных заправокполуфабрикатов, является одной из трудоемких и затратных технологий в производстве овощных консервов в целом. В то же время получение данной категории продуктов является достаточно перспективным направлением в овощеконсервной промышленности, так как использование консервированных пищевых продуктов (полуфрабрикатов) позволяет в значительной мере оптимизировать затраты времени и труда на приготовление пищи не только в домашних условиях, но и на предприятиях общественного питания. Дает возможность разнообразить меню и обеспечить население высококачественными продуктами на протяжении всего года [1].

На качество и вкусовые свойства готового продукта существенное влияние оказывает правильный выбор технологических параметров [2].

Одними из основополагающих параметров при производстве овощных консервов технологи называют тип нарезки овощей и способ термической обработки.

От способа измельчения ингредиентов, подготовленных для производства овощных консервов, во многом зависят органолептические свойства готового продукта, в том числе цвет и вкус. Исходя из этого, особое внимание следует обратить на однородность формы и размера нарезки основных ингредиентов. Они должны соответствовать форме основного продукта в готовом блюде. Это могут быть брусочки, кубики, соломка и др. [3, 4].

В технологии производства овощных консервов используют два основных приема термической обработки - пассерование и бланширование.

Пассерование - кратковременное обжаривание с небольшим количеством жира (растительного масла). Обычно пассеруют морковь, петрушку, сельдерей, томаты, лук для придания им особого вкуса и фиксации переходящих в жир ароматических красящих веществ. Для пассе- рования нарезанные овощи кладут в посуду слоем не более 4-5 см с разогретым до 130$140{ }^{\circ} \mathrm{C}$ жиром (15-20 \% к массе продукта) и обжаривают при перемешивании в течение 2025 мин при $110-120^{\circ} \mathrm{C}$.

Бланширование - кратковременная (5-7 мин) обработка продуктов кипящей водой (ошпаривание) или паром. Применяют для сохранения цвета, вкуса и консистенции овощей в процессе их последующей обработки [5].

Цель исследования: изучение влияния формы нарезки (измельчения) овощей и способа их термической обработки на органолептические свойства получаемых овощных консервов (борщевой заправки) и их сохранность.

Задача исследования: подобрать форму нарезки овощей для приготовления борщевой заправки, получить борщевую заправку с использованием различных приемов термической обработки овощей, провести органолептический анализ произведенной продукции, определить сроки хранения борщевой заправки.

Материалы и методы исследования. Для получения борщевой заправки применяли следующие виды сырья и материалы: свекла столовая свежая (ГОСТ 1722-85), морковь столовая свежая (ГОСТ 33540-2015), лук репчатый свежий (ГОСТ 1723-2015), томаты свежие (ГОСТ 1725-85), паста томатная (ГОСТ 3343-2017), масло подсолнечное (ГОСТ 1129-2013), сахар белый (ГОСТ 33222-2015), кислота уксусная для пищевой промышленности (ГОСТ Р 559822014), соль поваренная пищевая (ГОСТ Р 51 574-2000), вода питьевая (ГОСТ Р 51232-98).

Сырье, используемое для изготовления борщевой заправки, соответствовало требованиям технической документации.

Были использованы основные методы исследования: органолептические, микробиологические и статистические. Отбор проб готовой продукции для органолептической оценки, микробиологического контроля проводили стандартными методами (ГОСТ 8756.0-70). Определение микробиологических показателей готовых консервов включало выявление в нормируемых навесках дрожжей и плесневых грибов (ГОСТ 10444.12-88). Определение органолептических показателей (внешний вид, консистенция, цвет, вкус и запах) проводили с помощью количественного описательного анализа (ГОСТ 8756.1-2017) [6]. 
Результаты исследования и их обсуждение. Схема исследования влияния нарезки и способа термической обработки овощей для приготовления борщевой заправки представлена на рисунке 1.

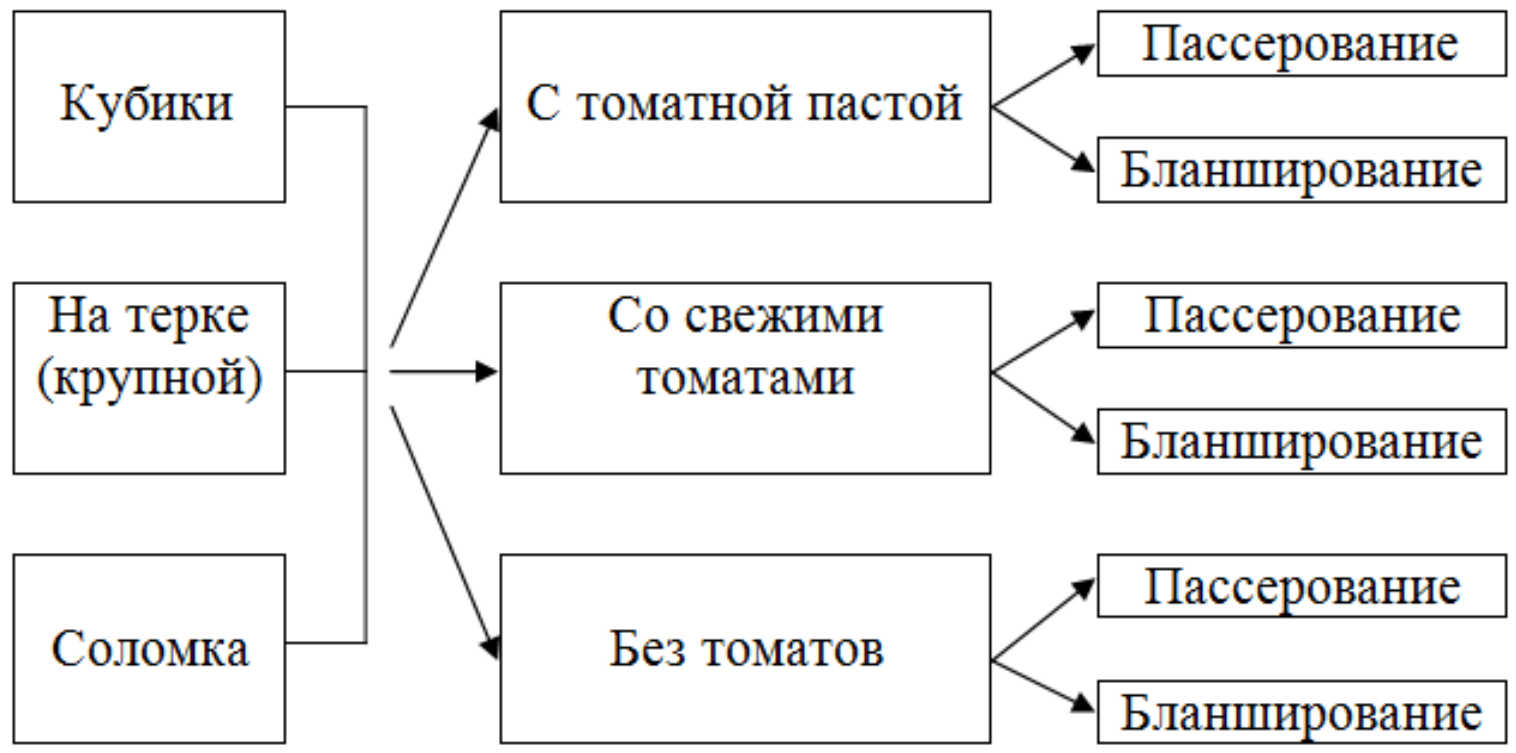

Pис. 1. Схема проведения экспериментальных исследований

Заготовленное сырье измельчали тремя способами:

1. Нарезка кубиками - свеклу, морковь, томаты нарезали на кусочки правильной формы с длиной ребра $1 \mathrm{~cm}$.

2. Измельчение на крупной терке.

3. Нарезка соломкой - нарезку овощей проводили в виде брусочков толщиной 1-2 мм, длиной 2,5 см [7].

Нарезка кубиками способствует равномерности термической обработки и равномерному приготовлению. Данный вид нарезки позволяет сохранить эстетический вид блюда и визуально делает акцент на отдельных компонентах блюда.

В результате измельчения сырья на крупной терке образуются полоски толщиной 0,2 см и длиной 1 см, что способствует равномерности распределения ингредиентов, входящих в состав борщевой заправки.

Нарезка соломкой подойдет для блюд, отличающихся нежной консистенцией и требующих быстрого приготовления. Данный вид нарезки часто применяют для приготовления соусов, салатов, супов.

Органолептическую оценку качества борщевой заправки, полученной при разных техноло- гических параметрах, проводили по ГОСТ 8756.1-2017.

Образцы борщевой заправки представлены в таблице 1.

Как показали исследования, чем крупнее нарезка сырья, тем более насыщенный цвет готового продукта. Цвет борщевой заправки изменялся от насыщенного красно-бордового (нарезка кубиками) до оранжево-красного (сырье натиралось на крупной терке). Немаловажное влияние на изменение цвета оказывал способ термической обработки. Овощи, подвергающиеся пассерованию, сохраняли насыщенные, яркие цвета от красно-бордового, бордового до оранжевокрасного. Бланшированные овощи были окрашены в бледные цвета красно-оранжевых и оранжевых оттенков.

Все образцы борщевой заправки по органолептическим свойствам соответствуют требования ГОСТ 18316-2013, но при этом имеют разные вкусовые особенности.

В работе была проведена дегустационная оценка полученных образцов и определены сроки хранения. Результаты представлены в таблице 2. 
Органолептические показатели (внешний вид) борщевой заправки, полученной при разных технологических параметрах

\begin{tabular}{|c|c|}
\hline Вид консервов & Внешний вид (цвет) \\
\hline Кубики с томатной пастой пассерованные & \\
\hline Кубики с томатной пастой бланшированные & \\
\hline На терке (крупной) с томатной пастой пассерс & \\
\hline На терке (крупной) с томатной пастой бланши & \\
\hline Соломка с томатной пастой пассерованная & \\
\hline Соломка с томатной пастой бланшированная & \\
\hline
\end{tabular}


Дегустационная оценка и сроки хранения борщевой заправки

Таблица 2

\begin{tabular}{|c|c|c|c|c|c|c|c|c|}
\hline \multirow[b]{2}{*}{$\begin{array}{c}\text { Вид } \\
\text { нарезки }\end{array}$} & \multicolumn{3}{|c|}{ Компонентный состав } & \multicolumn{2}{|c|}{ Термическая обработка } & \multirow[b]{2}{*}{$\begin{array}{l}\text { Вкусовые } \\
\text { качества }\end{array}$} & \multicolumn{2}{|c|}{$\begin{array}{l}\text { Срок хранения по- } \\
\text { сле вскрытия, сут }\end{array}$} \\
\hline & 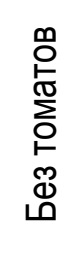 & 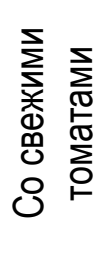 & 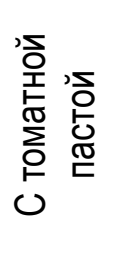 & 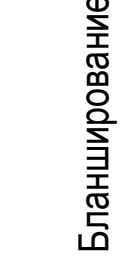 & 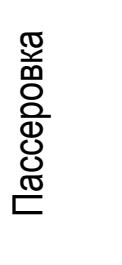 & & $+4^{\circ} \mathrm{C}$ & $+25^{\circ} \mathrm{C}$ \\
\hline \multirow{6}{*}{ Кубики } & & & + & + & & 7 & 15 & 5 \\
\hline & & & + & & + & 9 & 16 & 6 \\
\hline & & + & & + & & 7 & 14 & 4 \\
\hline & & + & & & + & 9 & 15 & 5 \\
\hline & + & & & + & & 7 & 15 & 5 \\
\hline & + & & & & + & 8 & 16 & 6 \\
\hline \multirow{6}{*}{ На терке } & & & + & + & & 9 & 13 & 4 \\
\hline & & & + & & + & 9 & 14 & 5 \\
\hline & & + & & + & & 8 & 12 & 4 \\
\hline & & + & & & + & 8 & 13 & 5 \\
\hline & + & & & + & & 7 & 13 & 4 \\
\hline & + & & & & + & 9 & 14 & 5 \\
\hline \multirow{6}{*}{ Соломка } & & & + & + & & 9 & 19 & 7 \\
\hline & & & + & & + & 10 & 20 & 8 \\
\hline & & + & & + & & 9 & 18 & 6 \\
\hline & & + & & & + & 10 & 19 & 7 \\
\hline & + & & & + & & 9 & 19 & 7 \\
\hline & + & & & & + & 9 & 20 & 8 \\
\hline
\end{tabular}

Проведенная сравнительная характеристика показала, что наиболее низкие баллы по органолептическим характеристикам набрал образец борщевой заправки, изготовленный без добавления томатов с применением метода термической обработки бланширование. Добавление в рецептуру свежих помидоров улучшает вкусовые свойства продукта, но при этом незначительно уменьшаются сроки хранения из-за большего количества воды в готовом продукте. Наилучшие результаты были отмечены в сроках хранения и качественных характеристиках борщевой заправки, полученной методом пассерования с добавлением томатной пасты.

Выводы. Подобрана форма нарезки сырья для производства овощных консервов (борщевой заправки) и способ термической обработки овощей, обеспечивающие наилучшие органолептические показатели готовой продукции.
Проведена дегустационная оценка потребительских свойств борщевой заправки.

Наилучшие результаты (10 баллов) были достигнуты при нарезке овощей соломкой и обработке методом пассерования. Данные образцы показали наиболее длительный срок хранения после нарушения герметичности упаковки. Полученные изделия по органолептическим показателям соответствуют ГОСТ 183162013 и могут быть рекомендованы для внедрения в производство.

\section{Литература}

1. Касьянов Г.И., Панина О.Р. Технология консервов «Первые обеденные блюда» // Тр. КНИИХП «Новые технологии - будущее пищевой промышленности». Краснодар: КНИИХП, 2003. С. 84-86. 
2. Бурова T.Е. Влияние обработки на состав и свойства растительного сырья: учеб.метод. пособие / под ред. А.Л. Ишевского. СПб., 2014. 85 c.

3. Сметанина Т.Л. Технология продукции общественного питания: учеб. пособие. Ч. 1. Кемерово, 2004.

4. Сметанина Т.Л., Подсосенко Т.В. Технология продукции общественного питания: учеб. пособие. Ч. 2. Кемерово, 2004.

5. URL: http://knigakulinara.ru/books/item/f00/s00/ z0000039/st119.shtml.

6. ГОСТ 8756.1-2017. Продукты переработки фрруктов, овощей и грибов. Методы определения органолептических показателей, массовой доли составных частей, массы нетто или объема. М.: Стандартинформ, 2017.

7. Родина Т.Г. Сенсорный анализ продовольственных товаров. М.: Академия, 2004. 208 с.

\section{Literatura}

1. Kasjanov G.I., Panina O.R. Tehnologija konservov "Pervye obedennye bljuda» // Tr. KNIIHP «Novye tehnologii - budushhee pishhevoj promyshlennosti». Krasnodar: KNIIHP, 2003. S. 84-86.

2. Burova T.E. Vlijanie obrabotki na sostav i svojstva rastitel'nogo syrja: ucheb.-metod. posobie / pod red. A.L. Ishevskogo. SPb., 2014. $85 \mathrm{~s}$.

3. Smetanina T.L. Tehnologija produkcii obshhestvennogo pitanija: ucheb. posobie. Ch. 1. Kemerovo, 2004.

4. Smetanina T.L., Podsosenko T.V. Tehnologija produkcii obshhestvennogo pitanija: ucheb. posobie. Ch. 2. Kemerovo, 2004.

5. URL: http://knigakulinara.ru/books/item/f00/s00/ z0000039/st119.shtml.

6. GOST 8756.1-2017. Produkty pererabotki fruktov, ovoshhej i gribov. Metody opredelenija organolepticheskih pokazatelej, massovoj doli sostavnyh chastej, massy netto ili ob\#ema. M.: Standartinform, 2017.

7. Rodina T.G. Sensornyj analiz prodovol'stvennyh tovarov. M.: Akademija, 2004. 208 s. 